\title{
The Influence of Educational,
}

Environmental and Social Factors

in the Decision to Attend Prenatal

Lectures among Pregnant Women

in Romania

Anca Maria BALASOIUa, Cristina-Diana POMANA ${ }^{a, b}$, Romina-Marina SIMA ${ }^{b, c}$, Liana PLES ${ }^{\mathrm{b}, \mathrm{c}}$

aDepartment PhD, IOSUD, „Carol Davila” University of Medicine and Pharmacy, Bucharest, Romania

bDepartment of Obstetrics and Gynaecology, "St John" Hospital, "Bucur" Maternity,

Bucharest, Romania

"Carol Davila" University of Medicine and Pharmacy, Bucharest, Romania

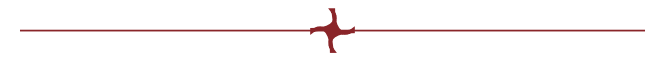

\begin{abstract}
- ABSTRACT
Introduction: Prenatal and postnatal education is an essential compound of prenatal care that prepares and facilitates the acquisition of women's skills, necessary for positive experiences during pregnancy, childbirth and postnatal period.

Material and methods: We conducted a prospective study that included pregnant women who attended prenatal courses. They were asked to fulfil a questionnaire about course topics, utility and impact on birth preparations. The pregnant women included in this group planned to give birth at Bucur Maternity, Saint John Clinical Hospital, Bucharest, Romania.

Results: A number of 205 pregnant women answered the online questionnaire over a period of two months. Their age range was between 25 and 35 years (40.98\%). Among them, 74.15\% had higher education, $85.37 \%$ of them were from urban areas, $82.44 \%$ were primiparous and $63.41 \%$ intended to have natural birth. There has been a growing interest for natural birth among pregnant women in their first pregnancy (68.05\%) and also for participating in pre- and postnatal education courses, which was influenced by the level of completed education $(65.66 \%$ of pregnant women with higher education wanted to give birth naturally). Topics of interest for most pregnant women are mentioned too.

Conclusions: In our study, the majority of participants were aware of the importance to get accurate information about the prenatal period, birth, childbirth and the next period, as well as the care of the new-born from specialized courses, provided by medical staff.
\end{abstract}

Keywords: educational education, pregnant women, social factors, environemnental factors

Address for correspondence:

Dr. Cristina-Diana Pomana

Tel.: +40 784172 083; email: dr.p.cristinadiana@gmail.com

Article received on the $5^{\text {th }}$ of October 2021 and accepted for publication on the $15 t^{\text {h }}$ of November 2021 


\section{INTRODUCTION}

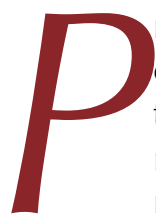

renatal and postnatal education is an essential tool that prepares and facilitates the acquisition of women's skills, necessary for positive experiences during pregnancy, childbirth and the postnatal period. (1)

Prenatal education is a powerful mean for disseminating information and discussing with parents about the period before and immediately after birth. The education of the expecting couples concerning pregnancy, birth and child care should be a priority for public services (2-4).

The purpose of this study was to demonstrate the importance of receiving accurate information about the prenatal period, birth and the postpartum period as well as the new-born care from specialized courses, provided by a trained midwife. Prior to research, the study protocol was approved by the Ethics Committee of Saint John Hospital, Bucharest, Romania.

\section{MATERIAL AND METHODS}

n a prospective study conducted over two months (from 25.06.2020 to 18.08.2020), pregnant women were asked to complete an online questionnaire about prenatal education. Subjects included in this group intended to give birth in Bucur Maternity Hospital, Saint John Clinical Hospital, Bucharest, Romania, and agreed to participate in the present study.

The inclusion criteria were as follows: the favourable health status of pregnant women, living foetus and their desire to give birth at Bucur Maternity. Singleton pregnancy did not represent an inclusion criterium.

The main questions were related to age, level of education, living environment, pregnancy age (trimester), parity, and correlation of these factors with the type of planned birth, intention to attend pre- and postnatal courses, alone or with their partners, respectively. The topics required for discussion in prenatal lectures included the necessity for support from the specialist and/or partner during the postpartum period, the utility of these courses and importance of recommending them to other couples.

The exclusion criteria in this study were strictly related to pregnant women's desire not to participate. Because the study period coincided with the COVID-19 pandemic, the questionnaire was distributed exclusively online.

Data were analysed using SPSS version 23.0 (statistical packages for social sciences). Pearson's correlation and two-sided $\mathrm{P}$ values of $<0.05$ were considered statistically significant. The risk of bias resulted from the subjectivity of respondents who completed the questionnaire.

\section{RESULTS}

The study included 205 pregnant women who accomplished the inclusion criteria. Regarding women's age it was found that $40.98 \%$ ( $n=84$ ) of them were between 25-30 years, $38.54 \%$ between $30-35$ years $(n=79)$, and less than $1 \%(n=2)$ over 40 years of age.

The group included $74.15 \%(n=152)$ pregnant women with high degree education and less than $1 \%(n=2)$ with minimum (primary) studies. A proportion of $5.37 \%(n=11)$ had postgraduate studies and $1.46 \%(n=3)$ doctoral studies. Within the study group, $85.37 \%$ $(n=175)$ of pregnant women lived in urban areas, and the minority in rural areas 14,63\% $(n=30)$. The majority of respondents were in the second and third trimester $57.56 \%(n=118)$ of pregnancy and only $3.9 \%(n=8)$ in the first trimester (up to 14 weeks) (Figure 1).

An interest finding was about the parity, that majority of $82.44 \%(n=169)$ pregnant women who completed the questionnaire were at their

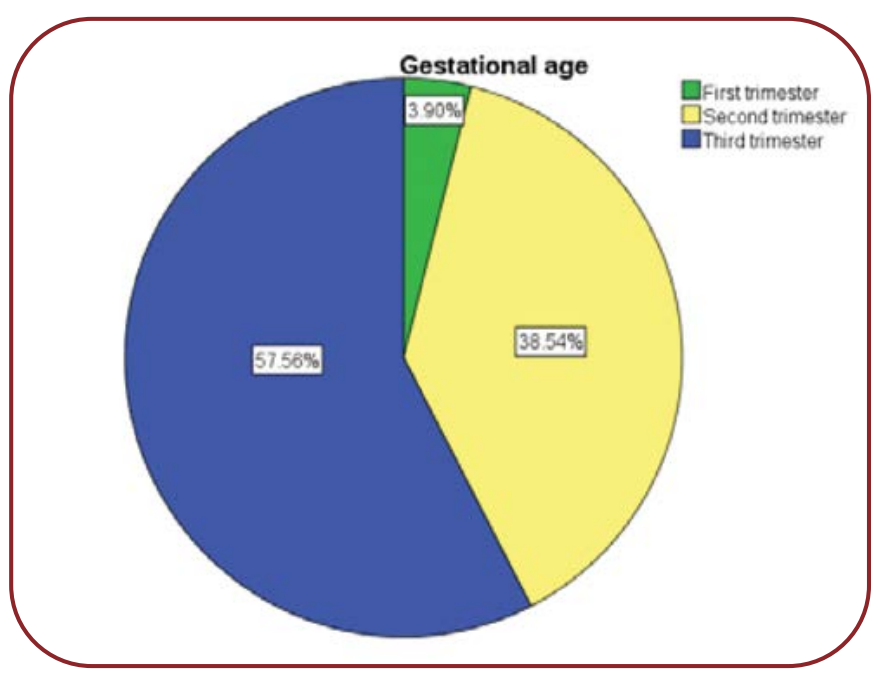

FIGURE 1. The responders distribution according to gestational age 


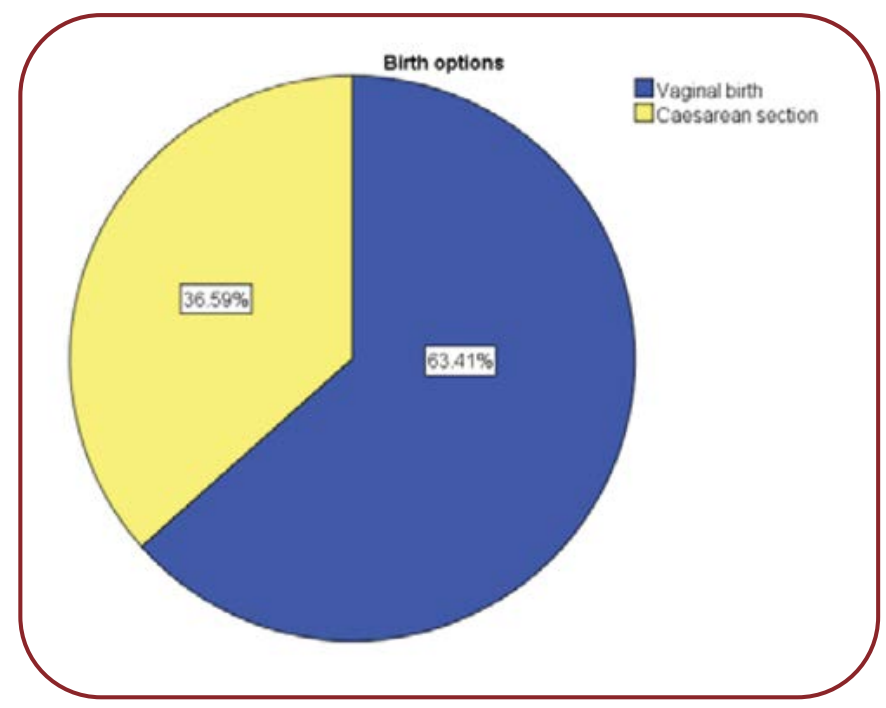

FIGURE 2. Birth option distribution

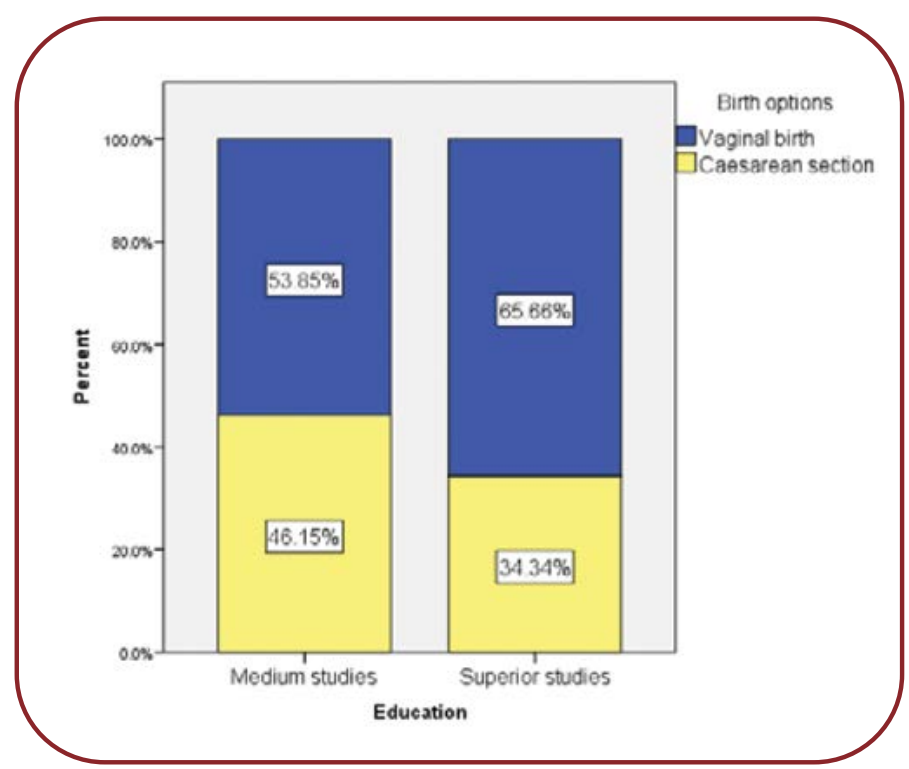

FIGURE 3. Patients distribution based on birth option and education

first pregnancy, and only $17.56 \%(n=36)$ of pregnant women had previous births.

A significant proportion of $63.41 \%(n=130)$ of women expressed their desire to have a natural birth (Figure 2). Searching for the correlation between parity and preference for a certain type of birth, it was found that $68.05 \%(n=115)$ of pregnant women in their first pregnancy wanted to have a natural birth, and those who have given birth (by caesarean section or naturally) preferred to give birth by caesarean section 58.33\% $(n=21)$. There was also a strong preference for the natural birth among pregnant women with higher education (65.66\%) (Figure 3).

Out of all 205 pregnant women included in the group, $86.8 \%(n=178)$ expressed their intention to attend pre- and postnatal education courses.

The interest towards prenatal course attendance differed in relation with the level of education: $80 \%$ of pregnant women with high education intended to attend prenatal courses and only $50 \%$ of those with low educational degree.

Of all subjects, 157 women at their first pregnancy $(93.45 \%)$ stated that they intend to participate in pre- and postnatal education courses. The intention to attend was lower for multiparous women (only $60 \%$ ). An increased interest $(92.31 \%)$ in pre- and postnatal education courses was also observed in pregnant women who planned a natural birth compared to those who opted for caesarean section $(79.45 \%, \mathrm{n}=58)$ (Figures 4 and 5).

Pregnant women in urban areas were more interested in pre- and postnatal education courses compared to those in rural areas, so that $89.6 \%$ (155 of all 173 subjects living in urban areas) of these stated that they intended to participate.

Among the questioned pregnant women, $73.66 \%(n=151)$ agreed that they relied on their partner to accompany them to pre- and postnatal education courses. The confidence was present mostly among women living in urban areas $(82.2 \%)$ and those who were at their first pregnancy (81.99\%). Pregnant women from urban areas were relying more on partners in terms of participation in pre- and postnatal education courses $(n=134)$.

Topics that pregnant women wanted to be discussed in pre- and postnatal education courses included new-born care [a topic that concerned $47.8 \%$ ( $n=98$ ) of pregnant women], breastfeeding/feeding the new-born $(45,4 \%$, $\mathrm{n}=93)$, birth $(26.8 \%, \mathrm{n}=55)$, maternal care during childbirth $(11.7 \%, \mathrm{n}=24)$, nutrition and hygiene in pregnancy $(9.8 \%, \mathrm{n}=20)$, and vaccination $(2 \%, n=4)$. Other topics that pregnant women were interested in included first aid for the baby, childhood illnesses, baby's sleep, postpartum depression, baby clothing, baby protection/safety devices at home or in the car, etc.

A percentage of $92.2 \%(n=189)$ of respondents considered that a prenatal education 


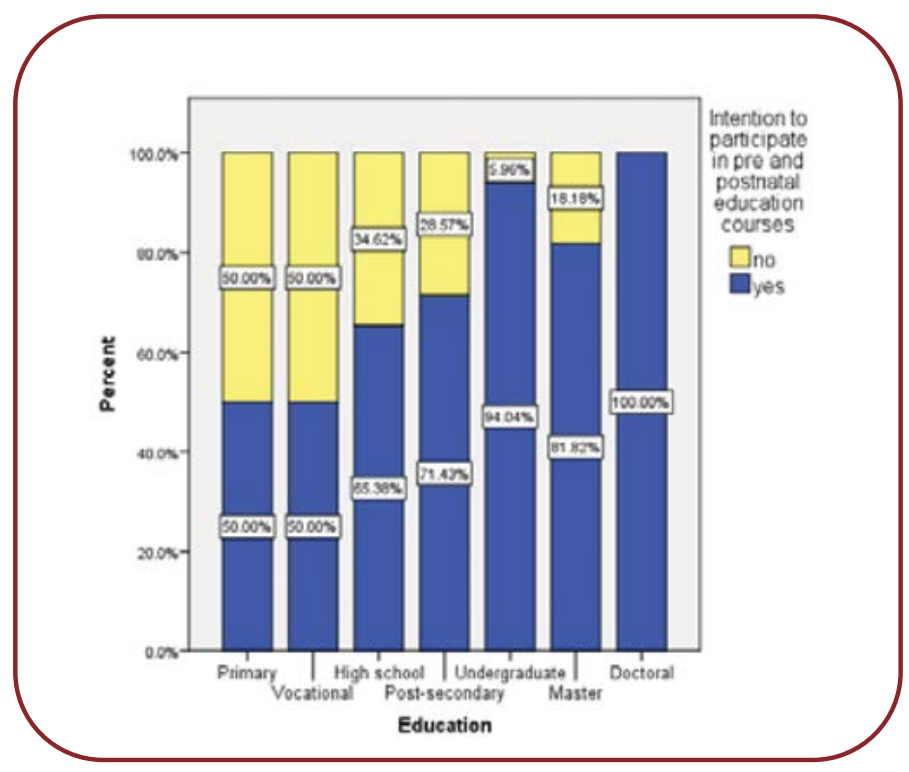

FIGURE 4. The intention to participate in prenatal education and education level

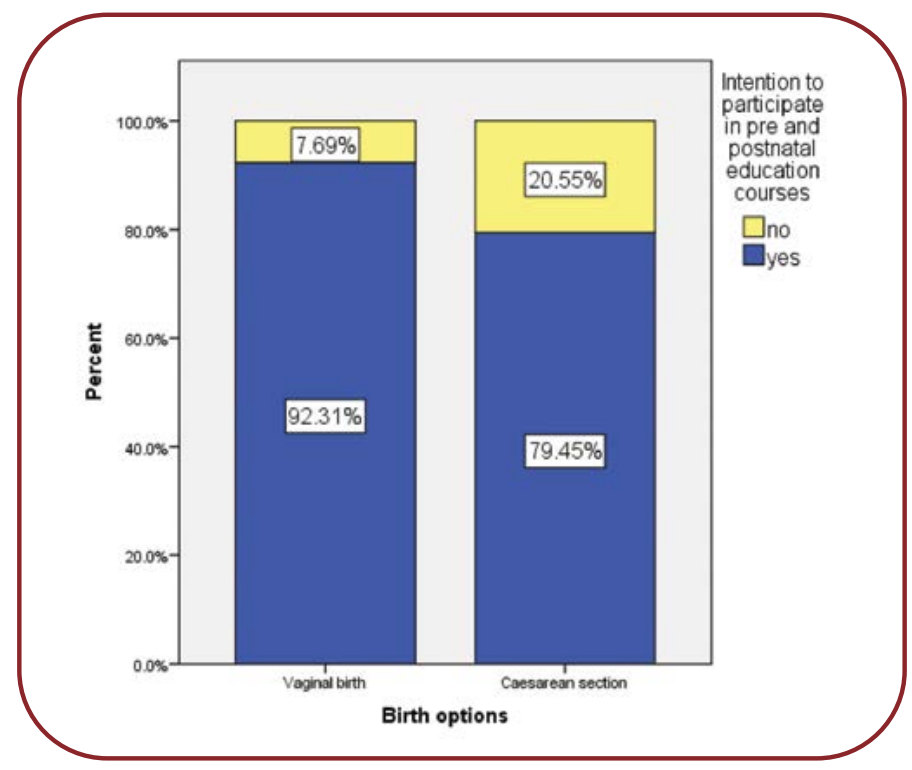

FIGURE 5. Birth options and intention to participate in prenatal and postnatal courses

course would help them with breastfeeding and only $5.4 \%(n=11)$ of them thought that the information was not useful; $94.67 \%$ (160) of all 169 primiparous pregnant women believed that a prenatal education course could help them with breastfeeding and $80.55 \%$ of pregnant women who have given birth appreciated the usefulness of the course in terms of breastfeeding. Pregnant women with higher education believed that the course of prenatal education regarding breastfeeding was more useful [95.18\%
( $n=158)$ of 161 pregnant women] compared to those with secondary education $[79.49 \%$ $(n=31)$ of the total of 39].

Pregnant women who planned a natural birth considered the course of prenatal education regarding breastfeeding more useful (96.15\%) compared to those who wanted a caesarean section $(85.33 \%)$.

A percentage of $97.6 \%(n=200)$ of respondents considered that they would need help during childbirth and $89.3 \%(n=183)$ relied on their partner, while $93.49 \%$ of primiparous women and $71.43 \%(n=25)$ of multiparous ones relied on their partner's support in breastfeeding.

Concerning new-born care, $97.6 \%$ of all pregnant women stated they would be helped by their partners, while $1 \%(n=2)$ admitted that they did not rely on their partner's support.

Regarding the benefit of pre- and postnatal education courses, $96.1 \%$ of pregnant women participating in the study intended to recommend the courses to future parents. Among primiparous pregnant women, $98.22 \%(n=166)$ and of those who gave birth before [81.11\% $(n=31)]$ would recommend them. The intention to recommend prenatal classes was stronger expressed among high educated respondents.

\section{DISCUSSIONS}

Drenatal education is a method of promoting health and wellbeing for both the mother and new-born. Studies have shown that prenatal education was an effective tool by reducing anxiety related to labour and birth and increasing partner's involvement in the neonate care. Lately, they opted for online prenatal education, especially during the pandemic (5). Women included in our study recognized the important role of pre- and postnatal training courses for themselves and their partners.

There are some ideas that prenatal education has a reduced efficiency due to the heterogeneity of delivery methods and its contribution is limited, especially for online prenatal education. However, online education may improve accessibility to prenatal courses (6-8). Our study results prove that educational, environmental and social factors influence the women's decision to attend pre- and postnatal training courses. 
More than three quarters of participants in the study group were middle-aged women (25-35 years old), and the majority had higher education and lived in urban areas. Most of the women included in the group were in the third trimester of pregnancy, primiparous and opted for vaginal birth. We correlated parity with the modality of birth and noticed that primiparous women planned to give birth naturally, while multiparous ones preferred caesarean section. The option for a certain type of birth was influenced by the level of education. Women with higher education wanted to give birth naturally. Primiparous women and those who have expressed their desire to give birth naturally were more interested in attending prenatal courses. There were no significant differences in intention to attend prenatal lectures between pregnant women from urban and rural areas, respectively. Pregnant women from urban areas rely more on partners for participation in pre- and postnatal education courses.

Topics of great interest at the courses were related to new-born care, breastfeeding, childbirth, maternal care, nutrition and hygiene during pregnancy or vaccination. Primiparous and women with higher education level considered that prenatal education course on breastfeeding was very useful. There were differences in the perception of prenatal education course between pregnant women who wanted to give birth naturally and those who preferred a caesarean section. Thus, the first category considered the course of prenatal education regarding breastfeeding the most important topic.

Almost all pregnant women believed that they needed help during childbirth and the majority declared that they would be supported by their partner. Primiparous women admitted that they would receive more help from their partner after birth in terms of breastfeeding compared to those who have given birth. Regarding the support of pregnant women in new-born care, most of them stated that they could rely on their partner.
The majority of pregnant women would recommend pre - and postnatal care courses to future parents, especially those at their first pregnancy or with higher education. Antenatal education increases mothers' understanding of basic new-born care. Mothers retain this knowledge into the early postpartum period and during early infancy; it was proved that this education might reduce morbidity and mortality (9). Lectures are efficient for mothers with a reduced level of education. Brief antenatal educational modules seem a feasible sustainable method for improving mothers' knowledge about new-born care $(10,11)$.

A study that included 212 pregnant women showed that changes about birth plans were influenced by prenatal educational classes and had an influence upon maternal birth preferences (12). There were significant differences in birth plan preferences prior to, and upon, completion of the prenatal classes (13). Another study that included 175 women from China showed that mothers who had a higher rate of attending all required prenatal examinations recovered faster after delivery compared to those who did not attend the prenatal education curriculum $(14,15)$. Prenatal education is indispensable for the improvement of maternal and child health, and thus, it should be advocated $(16,17)$.

\section{CONCLUSIONS}

/ omen included in the present study recognized the important role of pre- and postnatal training courses for themselves and their partners. They were aware of the importance of accurate information about the prenatal period, birth, postpartum period, or the new-born care from specialized courses, provided by medical staff. $\square$

Conflicts of interest: none declared.

Financial support: none declared.

\section{R}

1. Aida-Syahirah $\mathbf{H}$ Aji,

Faezah Awg-Manan, Yura-Rahayu

Abdullah, et al. Antenatal education for pregnant women attending maternal and child health clinics in Brunei Darussalam. Women Birth 2019;32:564-569.
2. Maria Chifuniro Chikalipo, Ellen Mbweza Chirwa, Adamson Sinjani Muula. Exploring antenatal 
education content for couples in

Blantyre, Malawi.

BMC Pregnancy Childbirth 2018;18:497.

3. Maiko Suto, Kenji Takehara,

Yumina Yamane, Ota Erika. Effects of prenatal childbirth education for partners of pregnant women on paternal postnatal mental health and couple relationship: A systematic review.

J Affect Disord 2017;210:115-121.

4. Enkin M, Keirse M, Neilson J, et al. A guide to effective care in pregnancy and childbirth. Oxford, UK: Oxford University Press, 2000.

5. Dumas L. Focus groups to reveal parents' needs for prenatal education.

The Journal of Perinatal Education 2002;11:1-9.

6. Martínez-Galiano JM,

Delgado-Rodríguez M. Effectiveness of the professional who carries out the health education program: perinatal outcomes.

Int J Womens Health 2014;6:329-334.

7. H., Niela-Vilen. Internet-based peer support for parents: a systematic integrative review.

Int J Nurs Stud 2014;51:1524-1537.

8. Romano AM. A changing landscape: implications of pregnant women's internet use for childbirth educators. J Perinat Educ 2007;16:18-24.

9. Augusto Pereira, Sara Cruz-Melguizo, Maria Adrien, et al. Clinical course of coronavirus disease-2019 in pregnancy. Acta Obstet Gynecol Scand 2020;99:839-847.

10. Weiner E, Billamay S, Partridge J, et al. Antenatal education for expectant mothers results in sustained improvement in knowledge of newborn care.

J Perinatol 2011;31:92-97.

11. Korzeniewski, Krzysztof. The pregnant traveller.

International Maritime Health 2018;69:63-69.

12. Barimani $M$, Forslund Frykedal $K$, Rosander M, Berlin A. Childbirth and parenting preparation in antenatal classes. Midwifery 2017;57:1-7.

13. Soriano-Vidal FJ, Vila-Candel $\mathbf{R}$, Soriano-Martín PJ, et al. The effect of prenatal education classes on the birth expectations of Spanish women. Midwifery 2018;60:41-47.

14. Yuhui Shi, Dongxu Wang, Yanfei Yuan, et al. The effect of prenatal education curriculum on mother's prenatal examination utilization, delivery mode and recovery status: a cross-sectional survey in China.

Environ Health Prev Med 2015;20:397-403.

15. Kim ES, Byun YC, Lee SH. A study on socioeconomic factors related to cesarean section in Korea.

Bogeon sahoe nonjib 1991;11:19-35.

16. Cormick G, Kim NA, Rodgers A, et al. Interest of pregnant women in the use of SMS (short message service) text messages for the improvement of perinatal and postnatal care. Reprod Health 2012;9:9.

17. Enkin M, Keirse M, Neilson J, et al. A guide to effective care in pregnancy and childbirth, $3^{\text {rd }}$ ed., 2000.

18. Mohammed A. Al-Ateeq, Amal A. Al-Rusaiess, Aida A. Al-Dughaither. Perceptions and effects of antenatal education. Saudi Med J 2013;34:1287-1293.

19. Qianling Zhou, Katherine Younger, John M Kearney. An exploration of the knowledge and attitudes towards breastfeeding among a sample of Chinese mothers in Ireland. BMC Public Health 2010;10:722.

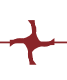

\section{FORMULAR DE ABONAMENT 2021}

\section{Ofertă valabilă până la 31.12.2021}

\author{
Abonament în format TIPĂRIT (bonus format ELECTRONIC - PDF) \\ 199 Lei $\square$ The British Medical Journal - Ediția în limba română (The BMJRo) \\ 149 Lei $\square$ Medica Academica (MA)
}

\section{Abonament în format ELECTRONIC (PDF)}

139 Lei $\square$ The British Medical Journal - Ediția în limba română (The BMJRo) 99 Lei $\square$ Medica Academica (MA)

109 Lei $\square$ Maedica - a Journal of Clinical Medicine* (Maedica)

*Publicație în limba engleză

Prețrile includ TVA.

Colegiul Medicilor din România acceptă la creditare abonamente numai la două reviste și acordă maximum 18 credite EMCD per revistă. Certificatul care atestă obținerea creditelor se eliberează nominal la sfârșitul perioadei de abonare, după rezolvarea corectă în proporție de minim $75 \%$ a chestionarelor și transmiterea acestora pentru evaluare.

\section{TARUS \\ B-dul Metalurgiei 78, Sector 4, 041836 București}

Media SRL_abonamente@tarus.eu, Tel.: +40213210190
Plata se poate face on-line, la abonamente.tarusmedia.ro sau prin mandat poștal ori ordin de plată în contul R078 BTRL RONC RTOV 05605503 deschis la Banca Transilvania, beneficiar TARUS Media S.R.L. (CUI: R018379900). Vă rugăm trimiteți o copie după mandatul poştal sau ordinul de plată, împreună cu talonul completat, prin poștă sau e-mail. Important: vă rugăm completaţi numele abonatului pe documentul de plată!

Nume

Prenume

CNP** CIF

(**Obligatoriu pentru eliberarea adeverinţei de punctaj şi/sau a diplomei) Instituţia

Profesia

Specializarea

Adresa corespondenţă

E-mail

Telefon Data plăţii

Detalii plată $\square$ mandat poştal $\square$ transfer bancar

Pentru o comunicare eficientă și preîntâmpinarea erorilor vă recomandăm să completați toate câmpurile. 